\title{
Hardiness as a Resource of Personality's Coping Behaviour in Difficult Situations
}

\author{
Milana R. Hachaturova \\ National Research University Higher School of Economics (Russia) \\ milanahse@mail.ru, mhachaturova@hse.ru
}

\section{Doi:10.5901/ajis.2013.v2n8p225}

\begin{abstract}
Coping behaviour plays a great role in solving a difficult, conflict situation. Hardiness cand be considered as a personality resource of coping behaviour in a conflict. In our research we use the following methods: S. Maddi's questionnaire (hardiness) and A. Heim's technique (coping strategies). 227 people, 108 men and 119 women, participated in the research. The correlation analysis has shown that strongly pronounced hardiness is connected with the choice of adaptive coping strategies, and feebly pronounced hardiness is a predictor of the choice of non-adaptive emotional strategies. Hardiness and its components - commitment and control, have a positive correlation with adaptive and relatively adaptive variants of cognitive, emotional and behavioural strategies and a negative correlation with the choice of non-adaptive strategies. Challenge has a negative correlation with adaptive behavioural strategies. In the conclusion, we show that studying the influence of hardiness on a person's choice of coping strategies in conflict situations can help to prevent similar conflicts in the future. As such, the findings of our research can be considered as a good prognostic and diagnostic tool.
\end{abstract}

Keywords: conflict, hardiness, commitment, control, challenge, personality resources, coping strategies.

\section{Introduction}

The social-psychological intensity and pace of modern life can lead to a great number of conflicts in different spheres. Destructive conflicts create negative effects, such as disorder, instability, and hostility and can result in the waste of a lot of material, time, cognitive and emotional resources. Conflicts slow down and complicate decision-making, reduce solidarity, lead to stress and negative emotional conditions (Antsupov \& Shipilov 1999).

Coping behaviour plays an important role in resolving interpersonal conflicts (Folkman \& Lazarus, 1998). Coping behaviour consists of the cognitive, emotional and behavioural efforts that an individual undertake to overcome difficult situations (Heim, 1988).

A coping strategy may be defined as a personality's actions in dealing with complex situations and adaptation to existing circumstances.

There are different classifications of coping behaviour in modern psychology. For example, R. Lazarus and S. Folkman considered problem-focused and emotionally-focused strategies (Folkman \& Lazarus, 1988). The former assume a cognitive estimation of existing difficult situation and search of possible ways of solution, the latter are directed to work with a personality's attitude to problems.

E. Heim suggested considering emotional, cognitive and behavioural strategies. These types of coping strategies involve behaviour that can be adaptive, relatively adaptive and non-adaptive in a conflict (Heim 1988).

E. Frydenberg considered coping behaviour depending on success in solving of existing problem and offered three categories of coping strategies: reference to other people, efficient and inefficient coping (Frydenberg, 2004).

D. Amirkhan viewed three groups of coping strategies - problem-solving, search for social support and avoiding (Amirkhan, 1994).

The issue of coping behaviour has a topic of research in the field of psychology since the 1960s and 1970s. In Russian psychology this problem has been actively researched the last two decades. Researchers involved in this area of study have focused on gender, age, professional experience, medical, social, and cultural conditions and contexts, and other features of coping behaviour (Holahan \& Moos, 1987; Endler \& Parker, 1990; Skinner, 1995; Folkman \& Lazarus, 1998; Amirkhan, 1999; Frydenberg, 2004; Bodrov, 2006; Caplan \& Schooler, 2007; Ryabinkina, 2007; Sircova, Mitina, 2008; Vodopianova, 2009). Nevertheless, there is a lack of research devoted to the interrelation of coping behaviour and conflict situations. While conflict interactions remain one of most urgent topics of a modern psychological science, features related to coping strategy choice in conflict situations are little-studied. 


\subsection{The Personality "Resources" of Coping Behaviour}

Recently, many psychologists have examined coping with difficult, conflict situations according to "the resource approach." This approach assumes the existence of specific personality features that help people to overcome difficulties (Hobfoll \& Lerman, 1988; Folkman \& Lazarus, 1998; Brissette et. al., 2002; Frydenberg, 2004; Bodrov, 2006; Belinskaya, 2009). These specific personality features can in turn define the choice of coping strategies within the context of a conflict.

Our analysis of psychological research allows us to suggest that a choice of coping strategies in conflict situations can be considered in connection with such personal resource as hardiness (Solcova \& Tomanek, 1994; Williams et al., 1995; Khoshaba \& Maddi, 1999; Aleksandrova, 2004; Loginova, 2009; Esschleman et al., 2010).

S. Maddi and his colleagues have revealed connection of optimism and hardiness with the choice of coping strategies. Indicators of hardiness and optimism had strongly pronounced correlations with coping behaviour. However, only components of hardiness were negatively connected with the choice of non-adaptive coping strategies (Khoshaba \& Maddi, 1999).

It is necessary to consider I. Solcova and P. Tomanek's researches, which testifies that a person with strongly pronounced hardiness is inclined to choose cognitive strategies and use more variants of behaviour when handling conflict (Solcova \& Tomanek, 1994). Hardiness has a positive correlation with the choice of effective coping strategies. Thus, it is negatively connected with the strategy of problem avoidance (Esschleman et al., 2010).

Researches of $\mathrm{P}$. Williams and $\mathrm{D}$. Vibe have shown that strongly pronounced hardiness has a positive correlation with the choice of adaptive coping strategies and a negative one - with the choice of non-adaptive strategies (Williams et al., 1995).

According to L. Aleksandrova, hardiness is a personality resource defining the ability to overcome difficulties. This difficulties can be usual and every day, but also - critical or extreme one. Hardiness includes such base personality's resources as cooperation, trust and creativity (Aleksandrova, 2004).

In M. Loginova's opinion, a person with strongly pronounced hardiness uses active coping strategies and overcomes stressful and difficult life situations, based on involvement and control of problems, ability not retreat in difficult conditions (Loginova, 2009). Юф Nevertheless, it is necessary to notice that there is a lack of modern psychological research devoted to investigating the correlation between hardiness and coping behaviour in conflict situations.

\section{Methodology}

As a result, the goal of this research is to investigate hardiness and its role in a personality's choice of coping strategies in conflicts situations.

This paper brings forward the following hypothesis: hardiness is connected with the choice of coping strategies in situations of an interpersonal conflict. Strongly pronounced hardiness has a positive correlation with the choice of adaptive cognitive and behavioural strategies and it is negatively connected with the choice of emotional strategies.

\subsection{Participants}

The sample included 227 participants, 108 of them were male and 119 of them female. The participants ranged in age from 18 to 53 years old (the median age was 31$)$. The participants were: students of Moscow universities $(n=86)$, and workers of different organizations $(n=141)$.

The participants were divided into three age groups:

- younger age group: under 25 years ( $n=79)$;

- middle age group: from 21 till 40 years $(n=71)$;

- senior age group: over 41 years $(n=77)$.

\subsection{Materials}

To prove the stated hypothesis we used the following materials:

- S. Maddi's questionnaire (Leontiev, Rasskazova, 2006).

- E. Heim's inventory (coping strategies) (Heim, 1988). It is worth noticing that according to E. Heim's technique, our respondents were offered to choose from the listed coping strategies of behaviour in a difficult situation the 
one that was most familiar to them. All strategies were subdivided into three types - cognitive, emotional and behavioural. There were adaptive, relatively adaptive and non-adaptive variants among them. It is important to mention that in the instruction to $\mathrm{E}$. Heim's technique the respondents were offered to choose from three described conflict situations the one they face most often. The given conflict situations were referred to three different spheres of human life - family, organizational and domestic. In case none of the listed conflict situations suited the respondents, they were offered to describe their own situation. And only after that the respondents marked different strategies of behaviour which they use to cope with this conflict situation.

\section{Results and Discussion}

SPSS 14.0 was used for statistical data processing. Data has been verified in the case of normal distribution by means of the Kolmogorov-Smirnov test, asymmetry and excess indicators. The obtained distribution of the variables, which were relevant to the personality features investigated, does not differ from a normal distribution. This allows us to use parametrical techniques.

Firstly, it is necessary to consider respondents' preferences in the choice of coping strategies in a situation of interpersonal conflicts. Our research testifies that the most preferred coping strategies of behaviour in a conflict situation are cognitive ones - they were chosen by $48 \%$ of respondents. Thus, $33 \%$ of the interrogated respondents prefer behavioural strategies, and only $19 \%$ - emotional strategies. It is an important point to be made that among all types of coping strategies in almost $50 \%$ of cases their adaptive variant prevails over others.

Besides, the results of the research allow us to state that there are gender features of coping strategies' choice in a conflict situation. In interpersonal conflicts women most often resort to emotional coping strategies (38\% of respondents). While the majority of men (62\% of respondents) prefers cognitive variants of coping strategies. Emotional strategies have appeared the least popular among men, they were chosen only by $7 \%$ of the respondents. Also the given differences have been confirmed statistically (Mann-Whitney Coefficient $p<0.05$ in the choice of emotional strategies). Thus, among variants of coping strategies men prefer adaptive cognitive strategies ( $47 \%$ of respondents).

It can be explained by the fact that generally women interpret emotions of others better; they also express their emotions better. At the same time, men tend to analyse the existing conflict, think of possible ways of its solving and try to undertake any actions to cope with it. It is important to notice that these features are not predetermined gender characteristics; they correspond to the social environment's expectations in a large extent.

The results of coping strategies' choice have been also analysed according to the respondents' age differences. As it has been already mentioned, our respondents have been divided into three groups. Our research indicates that among all three age groups the choice of cognitive strategies prevails. Thus, the peak of this choice is in the second age group ( $47 \%$ of respondents), and is gradually falling with increase of the respondents' age to $30 \%$. The highest percentage (35\% of respondents) of behavioural strategies' choice is in the third age group (respondents over 46 years). The choice of emotional strategies practically doesn't vary depending on the respondents' age and has averaged $26 \%$ of all respondents. Also it is necessary to mention that among all three variants of coping strategies the choice of adaptive strategies is the highest in the senior age group.

One of our explanations of this fact is that the older a person gets, the more experience in conflict resolution he or she has, being capable in some cases to anticipate possible conflicts. It allows a person to solve another conflict situation with fewer losses.

The prevalence of cognitive strategies in the senior age groups can be explained in the following way. In a pubertal period and in youth a person can have a strong emotional reaction in a difficult situation, concede conflict escalation instead of trying to stop it at the beginning. In the mature age people are inclined to consider possible ways of conflict resolution and consequences of their actions before undertaking something. Therefore, at this age adaptive cognitive and behavioural strategies are on the foreground.

The results of correlation analysis allow us to find the connection of the choice of coping strategies with hardiness and its components. All statistically significant correlations are in Table 1.

Hardiness as a whole and one of its components - commitment, has a positive correlation with adaptive and relatively adaptive variants of cognitive, emotional and behavioural coping strategies. They are negatively connected with the choice of non-adaptive tactics. 
Table 1. Pearson correlation between the choice of coping strategies and hardiness and its components

\begin{tabular}{|c|c|c|c|c|}
\hline $\begin{array}{ll}\text { Strategies } & \text { Features } \\
\end{array}$ & Hardiness & Commitment & Control & Challenge \\
\hline Analysis of problem & $0.127^{*}$ & 0.111 & $0.153^{*}$ & -0.023 \\
\hline Self-possession & $0.244^{* *}$ & $0.365^{\star *}$ & $0.354^{\star \star}$ & -0.134 \\
\hline Awareness of own importance & $0.278^{\star \star}$ & $0.359 * *$ & $0.212^{\star}$ & -0.111 \\
\hline Relativity & 0.072 & 0.123 & 0.145 & 0.034 \\
\hline Religiousness & $0.114^{*}$ & $0.199 *$ & -0.089 & 0.078 \\
\hline Searching for sense & 0.094 & 0.124 & $-0.113^{\star}$ & -0.095 \\
\hline Ignoring & $-0.257^{\star \star}$ & $-0.284^{\star \star}$ & $-0.344^{\star \star}$ & 0.116 \\
\hline Humility & $-0.297^{\star *}$ & $-0.282^{\star \star}$ & -0.213 & 0.125 \\
\hline Dissimilation & $-0.166^{\star}$ & $-0.262^{\star \star}$ & 0.078 & -0.056 \\
\hline Confusion & 0.201 & -0.075 & 0.113 & 0.078 \\
\hline Protest & $0.321^{*}$ & $0.231^{*}$ & 0.078 & 0.121 \\
\hline Optimism & $0.318^{\star \star}$ & $0.317^{\star *}$ & $0.215^{*}$ & 0.007 \\
\hline Emotional relief & $-0.188^{*}$ & 0.156 & $-0.178^{*}$ & -0.067 \\
\hline Passive cooperation & $-0.182^{\star}$ & $0.123^{*}$ & $-0.179 *$ & -0.089 \\
\hline Suppression of emotions & $-0.345^{\star *}$ & $-0.355^{\star *}$ & $-0.322^{\star *}$ & -0.129 \\
\hline Obedience & $-0.241^{*}$ & $-0.255^{\star \star}$ & $-0.214^{*}$ & 0.156 \\
\hline Self-accusation & 0.122 & -0.116 & 0.106 & 0.123 \\
\hline Aggression & $-0.134^{*}$ & $-0.186^{*}$ & $-0.155^{\star \star}$ & 0.087 \\
\hline Cooperation & $0.131^{*}$ & $0.216^{*}$ & $0.177^{*}$ & $-0.378^{*}$ \\
\hline Altruism & $0.262^{\star \star}$ & $0.367^{* *}$ & $0.212^{*}$ & -0.115 \\
\hline Communication & $0.332^{\star \star}$ & $0.398^{* \star}$ & $0.306^{*}$ & 0.119 \\
\hline Distraction & 0.145 & 0.115 & -0.149 & -0.089 \\
\hline Indemnity & 0.098 & $0.155^{\star \star}$ & 0.117 & 0.098 \\
\hline Constructive activity & $0.122^{*}$ & $0.149^{* \star}$ & -0.098 & 0.009 \\
\hline Active avoidance & $-0.333^{\star \star}$ & $-0.281^{\star \star}$ & $-0.308^{*}$ & 0.176 \\
\hline Retreating & $-0.412^{\star \star}$ & $-0.389 * \star$ & $-0.338^{*}$ & 0.189 \\
\hline
\end{tabular}

* - significance level $p \leq 0.05$

** - significance level $p \leq 0.01$

It is important to notice that control has strong correlations with the choice of adaptive cognitive, behavioural and emotional strategies. Thus, control has a negative connection with the choice of relatively adaptive and non-adaptive strategies.

Besides, challenge has only one statistically significant correlation. It is negatively connected with the choice of cooperation - adaptive behavioural strategy.

Our results allow us to suggest that a personality with feebly marked hardiness uses emotional strategies in conflicts, and a personality with strongly pronounced hardiness prefers behavioural and cognitive coping strategies. Besides, strongly pronounced hardiness assumes the choice of adaptive variants of behaviour. Low level of hardiness, on the contrary, is connected with preference of relatively adaptive and non-adaptive coping strategies with a conflict situation.

Hereby, a personality with strongly pronounced hardiness does not avoid conflicts, ignoring incipient problems, does not retreat in the face of difficulties, and, on the contrary, tries to analyse a problem, to find possible variants of solving. He or she does not accept a conflict, does not try to consider it as something insignificant and unimportant.

Our results testify that respondents with strongly pronounced hardiness prefer rational analysis of conflicts, try to create ways of its solving. They do not choose such strategy as suppression of emotions, obedience and self-accusation or, on the contrary, aggression. They are optimistic and sure that they can find solving of any conflict situations. They protests against the circumstances. Seldom people with strongly pronounced hardiness can be lost in a conflict situation, they keep their self-control and self-possession, believe in own ability to cope with a conflict. And only in most difficult situations they can use social support and help of other people.

The research indicates that a personality with strongly pronounced commitment has ability to cope with negative emotions in conflicts. Thus, his or her actions are also adaptive. A personality does not avoid conflicts; he or she uses 
such strategies as altruism, cooperation and communication with other people. He or she even in a conflict tries to find possibilities for progress. This conclusion has been proved in a number of other researches (Khoshaba \& Maddi, 1999; Loginova, 2009).

Besides, the results of our research allow us to state that a personality with strongly pronounced control tries not to ignore a difficult situation. He or she keeps self-control, tries to find constructive ways of conflict solving. He or she believes in own ability to overcome a conflict situation. A personality understands that only his or her own active actions, control the circumstances, and interaction with other people can lead to effective solving of a conflict situation.

The statistical analysis has shown that challenge is significant negative correlated with the choice of an adaptive behavioural strategy - cooperation. We can explain it by the fact that a personality with feebly marked challenge is afraid to be accountable for own actions and decisions in conflicts. Therefore, he or she tries to use help of other people which can increase their chances to solve a conflict effectively.

As a result, the hypothesis formulated in the research has been partially confirmed.

\section{Findings}

Our research allows us to make the following findings.

1. A person's choice of coping strategies in a conflict situation has gender specificity. Women chose emotional strategies more often while men prefer cognitive ones.

2. Strongly pronounced hardiness is connected with the choice of adaptive coping strategies and feebly pronounced hardiness is a predictor of the choice of non-adaptive emotional strategies.

3. Hardiness and its components - commitment and control, are positively connected with the choice of adaptive and relatively adaptive variants of cognitive, emotional and behavioural strategies and are negatively correlated with the choice of non-adaptive strategies.

4. Challenge is negative correlated with adaptive behavioural strategies.

\section{Conclusion and Future Research}

This study provides examination of the role of hardiness in coping with an interpersonal conflict. The connections ascertained in this research between hardiness and coping strategies in conflict situations can help to prevent similar conflicts in the future. Indeed, the research material can be used in psychological training and consultation and can be a good prognostic and diagnostic tool.

Our future researches will be connected with examining particular features of personality resources of coping with difficulties in a context of dispositional and situational factors.

\section{References}

Aleksandrova, L.A. (2004). O Koncepcii Zhiznestoykosti v Psikhologii (About Concept of «Hardiness» in Psychology) // Proceedings of «Siberian psychology today». Kemerovo: Kyzbassvyzisdat. p. 82-90.

Amirkhan, J.H. (1994). Criterion Validity of a Coping Measure // Journal of Personality Assess, volume 62, № 2, pp. 242-261.

Antsupov, A.A., Shipilov, A.I. (1999). Konflictologiya (Conflictology) Moscow: Unity, 591.

Belinskaya, E.P. (2009). Koping Kak Socialno-psichologicheskaya Problema (Coping as a Socially-psychological Problem) (electronic resources). Psikhologicheskie Issledovaniya (Psychological Researches), volume 1. Accessed from http:// psystudy.ru.

Bodrov, V.A. (2006). Psikhologicheskii Stress: Razvitie i Koping (Psychological Stress: Development and Coping). Moscow: PER SE, 528.

Brissette, I., Scheier, M., Carver, C. (2002). The Role of Optimism and Social Network Development, Coping and Psychological Adjustment during a Life Transition // Journal of Personality and Social Psychology, volume 82, pp. 102-111.

Caplan, L.J., Schooler, C. (2007). Socioeconomic Status and Financial Coping Strategies: The Mediating Role of Perceived Control. Social Psychology Quarterly, volume 70.

Endler, N.S., Parker, J.D. (1990). Multidimensional Assessment of Coping: A Critical Evaluation // Journal of Personality and Social Psychology, volume 58.

Esschleman, K.J., Bowling, N.A., \& Alarcon, G.M. (2010). A meta-analytic examination of hardiness // International Journal of Stress Management. Volume 17, №4. pp. 277-307.

Folkman, S., Lazarus R. (1998). Coping as a mediator of emotion // Journal of Personal and Social Psychology. Volume 54. pp. 466-475.

Frydenberg, E. (2004). Coping Competencies // Theory into Practice, volume 1.

Heim, E. (1988). Coping and Psychosocial Adaptation // Journal of Mental Health Counseling, volume 10, pp. 136-144.

Hobfoll, S.E., Lerman, M. (1988). Personal relationships, personal attitudes, and stress resistance: mother's reactions to the child's 
illness // American Journal of Community Psychology. Volume 16, №4. pp. 565-589.

Holahan, C.J., Moos, R.H. (1987). Personal and Contextual Determinants of Coping Strategies. Journal of Personality and Social Psychology, volume 52.

Khoshaba, D., Maddi S. (1999). Early Antecedents of Hardiness // Consulting Psychology Journal. Volume 51. pp. 106-117.

Lazarus, R., Folkman, S. (1988). Manual for Ways of Coping Questionnaire // Palo Alto, CA.

Leontiev, D.A., Rasskazova, E.I. (2006). Test Zhiznestoykosti (Hardiness Test) Moscow: Smysl.

Loginova, M.V. (2009). Zhiznestoykost kak Klyuchevoi Vnytrilichnostnyi Resyrs (Hardiness as Intrapersonal Key Resource) // Bulletin of Moscow University of MVD. Volume 6, pp. 19-22.

Ryabinkina, I.V. (2007). Structurnaya organizatiya vremennoi perspectivy starsheklassnikov s raznym yrovnem yspeshnosti (The structural organization of time perspective of senior pupils with different level of educational success): Dissertation abstract (PhD in psychology), Saint-Petersburg.

Skinner, E.A. (1995). Perceived Control, Motivation, and Coping. Newbury Park: Sage Publications.

Sircova, A., Mitina, O.V. (2008). Vozrastnaya Dinamika Vremennoi Perspectivy Lichnosty (Ade Dynamics of Personality's Time Orientations). Voprosy Psikhologii, volume 2.

Solcova, I., Tomanek, P. (1994). Daily stress coping strategies: An effect of hardiness // Studia Psychologica. Volume 36. pp. 390-392.

Vodopianova N.E. (2009). Psikhodiagnostika Stressa (Psychodiagnostics of Stress). St.Petersburg: Piter. - 329 p.

Williams, P.G., Wiebe, D.J., \& Smith T.W. (1995). Coping processes as mediators of the relationship between hardiness and health /I Journal of Behavioural Medicine. Volume 15. pp. 237-255. 